\title{
Hole-making processes and their impacts on the microstructure and fatigue response of aircraft alloys
}

\author{
Dan Sun ${ }^{1}$ (D) Patrick Lemoine ${ }^{2} \cdot$ Daniel Keys $^{1} \cdot$ Patrick Doyle $^{2} \cdot$ Savko Malinov $^{1}$ • \\ Qing Zhao ${ }^{3}$ Xuda Qin $^{3} \cdot$ Yan Jin ${ }^{1}$
}

Received: 18 August 2016 / Accepted: 28 November 2016/Published online: 14 December 2016

(C) The Author(s) 2016. This article is published with open access at Springerlink.com

\begin{abstract}
A comparative study on conventional drilling and helical milling has been reported under the context of aircraft alloy hole making. The impacts of these two different machining processes on the microstructures and the fatigue performance of different aircraft alloys have been elaborated. Results show that both alloys undergo more severe surface/subsurface plastic deformation under conventional drilling comparing to helical milling process. Helical milling leads to a longer coupon fatigue life compared to conventional drilling for both alloys. The fatigue life of $\mathrm{Al} 2024-\mathrm{T} 3$ is significantly longer than that of Ti-6Al-4V under all machining conditions. The use of coolant generally produces less damaged surface and leads to enhanced fatigue performance of the machined alloys. In addition, the machined surface roughness has been studied to further elaborate the effects of different machining processes.
\end{abstract}

Keywords Aircraftalloys $\cdot$ Drilling $\cdot$ Helical milling $\cdot$ Fatigue

\section{Introduction}

Ensuring the reliability of aircraft is a primary concern for aircraft designers and manufacturers. Aircrafts constantly

Dan Sun

d.sun@qub.ac.uk

1 School of Mechanical and Aerospace Engineering, Queen's University Belfast, Belfast BT7 5AH, UK

2 The Nanotechnology and Integrated BioEngineering Centre, Ulster University, Newtownabbey BT37 0QB, UK

3 Tianjin Key Laboratory of Equipment Design and ManufacturingTechnology, Tianjin University, Tianjin City 300072, People's Republic of China operate under vibration/shock conditions and thousands of fastener holes where fuselage skin panels are attached together are prone to fatigue. High-cycle fatigue, in which fatigue failure occurs due to repeated cyclic loading below the material yield strength, is a very important consideration for aerospace engineers. Based on records and historical data, fatigue is responsible for 55\% of in-service failures of aircraft components, whereas the second most common failure mechanism, corrosion, accounts for just $16 \%$ of failures [1]. As fastener holes produce regions of concentrated stress where fatigue cracks can initiate and propagate, they play a critical role in the fatigue life of aircraft structures and are relevant to ensuring both good performance and reliability of the aircraft.

Aircraft fuselage skins are commonly made of aluminum alloys and titanium alloys [1]. Manufacturing processes can unintentionally alter the material properties and often induce residual stresses which can affect its fatigue life. Typically, fastener holes are made by hand using the conventional drilling process, whereby a rotating drill feeds into the fuselage skin. Conventional drilling involves a rotating cylindrical tool bit which has two cutting edges at the working end and feeds into the workpiece. Metal is extruded by the chisel edge and shear cutting is performed by the lips of the tool [2]. During the conventional drilling process, the material is removed when the chips are transported laterally and then evacuated through the flutes. This translates into a high thrust force and effective dissipation of heat is difficult [3]. The necessity for chips to be removed through the bore during drilling means there is an inherent interference with lubrication and cooling. Friction between the drill, chip and fuselage skin can increase the surface roughness of the hole which can provide stress concentration zones from which fatigue cracks can initiate $[4,5]$.

Most drilling processes also result in a burr on both sides of the workpiece of which the larger exit burr is the main 
concern, particularly in titanium alloys [6]. Despite some of the problems explained, conventional drilling is the dominant hole-making process in the aerospace industry. For the manufacturing of aircraft wings alone, it is reported that 40 million holes are drilled annually in one assembly line [7].

Helical milling is an emerging technology which involves a milling tool travelling on a helical path into the work piece. The cutting process is intermittent and the material removal is done in the form of small chips formed by each milling cutter tooth. The helical milling process has been shown to have a number of advantages over conventional drilling. In a comparative study between helical milling and conventional drilling of Ti-6Al-4V, results showed a much lower cutting force, better hole quality and excellent machinability in helical milling [8]. In a study of helical milling of aluminum alloy with minimum quantity lubrication, Sasahara et al. [9] observed reduced shape error and burr formation, lower machining temperatures and smaller cutting force compared to dry conventional drilling. Iyer et al. [3] have shown that helical milling is capable of machining $\mathrm{H} 7$ ( $\mathrm{H} 7$ is the standard drilled hole tolerance for aerospace metals and requires that the diameter does not vary by more than $0.01 \mathrm{~mm}$ [10]) holes with a surface finish of $0.3 \mu \mathrm{m}$ Ra such that the need for reaming is eliminated in AISI D2 steel. In a recent study completed by Li et al. [11] on evolution of tool wear and its influence on borehole quality in dry helical milling of Ti-6Al-4V alloy, bettermachined hole quality was observed at the end of the tool life. This study found that surface roughness was not sufficient to fully evaluate the quality of the machined surface after microsmearing was observed in holes produced near the end of the tool life. This is an important observation because smearing can cover surface detects which can cause fatigue failure, which is unacceptable in the aerospace industry. The study also suggested that the hole quality should be evaluated by measuring geometry accuracy (hole diameter and roundness error), burr formation, and surface roughness. Olvera et al. [12] showed that ball helical milling was able to produce holes in titanium alloy with an average surface roughness of $0.6 \mu \mathrm{m}$, compared with $1 \mu \mathrm{m}$ for conventional drilling. However, this study also found that ball helical milling caused a greater reduction in microhardness: an average drop of 13 HRC was observed for helical milling compared to a drop of only 6 HRC for drilling. It was suggested that the higher cutting speeds and machining temperatures in helical milling induced thermal softening, which countered the dominant strain hardening [13]. Due to the poor machinability of titanium alloys, the alloy surface is easily damaged during machining and studies have shown significant microstructure alteration and smearing appearing as a white layer in microstructural analysis $[14,15]$.

From the reviewed literature, it is mostly agreed that for aluminum alloys, titanium alloys and steels, helical milling tends to produce better quality holes as compared to conventional drilling. The fact that helical milling resulted in a significant reduction in burr formation could result in a $30 \%$ saving in the manufacturing cost of some aircraft components [16]. Despite the reported advantages, studies concerning microstructures of machined materials and their fatigue performance are limited for the emerging helical milling process. This study aims to investigate the impacts of the conventional drilling and helical milling processes on the microstructural change as well as the fatigue response of two commonly used aircraft alloys, namely Al 2024-T3 and Ti-6Al-4V (grade 5 titanium alloy). In addition, other properties such as machined hole surface roughness have also been studied in details.

\section{Experiment}

The Al 2024-T3 alloy (solution treated, cold worked and naturally aged) was purchased in sheet form $(2.286 \mathrm{~mm}$ in thickness) from LAS Aerospace Ltd. The alloy meets the requirements of AMS-QQ-A-250/5. The ASTM grade 5 Ti-6Al-4V sheet had a thickness of $2.54 \mathrm{~mm}$ and was kindly supplied by Vulcanium Metals International. The titanium sheet has been hot rolled, annealed, descaled and levelled to meet the requirements of AMS 4911L.

The helical milling cutters used in the tests were ultra-finegrain carbide (ISO K10) kindly supplied by the School of Mechanical Engineering, Tianjin University, China. The composition of the cutter matrix is WC-8\% Co and the thickness of the TiAlN coating is $1-3 \mu \mathrm{m}$. These tools have four teeth, with an overall length of $55 \mathrm{~mm}$, a cutting edge length of $4 \mathrm{~mm}$ and a cutting edge diameter of $6 \mathrm{~mm}$. The helix angle is $35^{\circ}$, clearance angle is $15^{\circ}$ and the rake angle is $5^{\circ}$. High speed steel (HSS 5523, Guhring Ltd) twist drill bits were chosen for drilling aluminium because they are still the most commonly used type in the aerospace industry. Due to the very low cutting speeds required for using HSS drill bits in drilling titanium (to reduce heat generation, especially under dry conditions), carbide twist drills (Guhring Ltd. tool number 5517, made of grade K carbide with two teeth) were chosen so that drilling parameters could be kept similar for both materials.

Fatigue coupons were produced on a MIKRON UCP 600 five-axis machining centre capable of a maximum spindle speed of 12,000 rpm. The helical milling feed was achieved by motion compensation of the machining centre. The detailed helical milling kinematics can be found in Fig. 1. The borehole is generated by a milling tool which travels in a helical path in the workpiece. The three motions involved in helical milling process are orbital rotation, spindle rotation and axial feed. The helical milling parameters are as follows: $D t$, tool diameters $(\mathrm{mm}) ; D h$, borehole diameters $(\mathrm{mm}) ; n$, spindle rotation speed (rpm); $n p$, orbital rotation speed (rpm) and $a$, feed rate in axial direction per orbital rotation ( $\mathrm{mm}$ per revolution). 
Fig. 1 Schematic of the helical milling process [17]
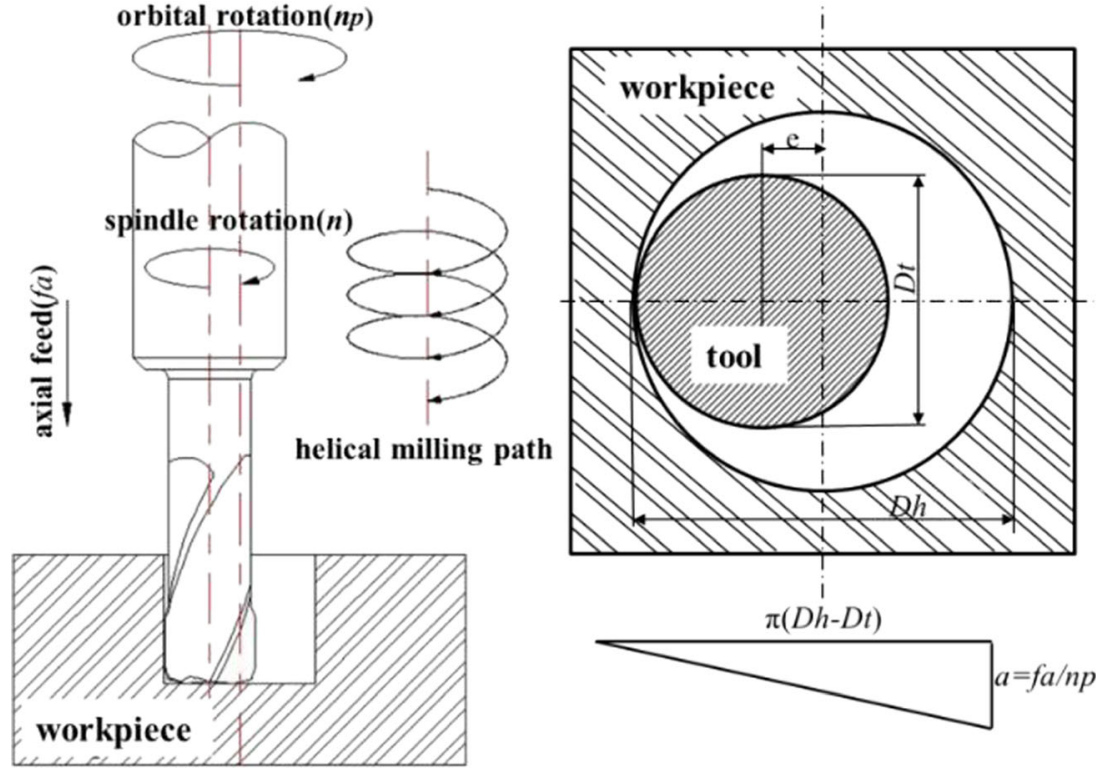

The cutting conditions used for helical milling and drilling are shown in Table 1 and are within the limits recommended by the tool manufacturers. For machining of coupons using external flooded coolant conditions, water soluble coolant which contained $8-10 \%$ oil was used.

Seven fatigue coupons were tested on an Instron 1343 servohydraulic fatigue testing machine and conditions are outlined in Table 2. All fatigue tests were done in compliance with ASTM E466-07.

In order to enable microstructural analysis around the machined holes, an additional coupon was wire-cut through the centre of the hole using electrical discharge machining (EDM) and the surface was polished and etched for further observation using a FEI Quanta FEG 250 scanning electron microscope (SEM). The polished Al 2024-T3 coupons were swab etched with Keller's etch for $20 \mathrm{~s}$, and Kroll's reagent was used to swab etch the titanium specimens for $30 \mathrm{~s}$. Surface roughness values of the machined holes were measured using a TESA RUGOSURF 10G portable roughness gauge according to ISO 4287 with a cut-off length of $0.8 \mathrm{~mm}$. Measurements were taken at three positions spaced at $90^{\circ}$ intervals to obtain the average surface roughness. The main surface roughness parameter used in this study was an arithmetic mean average surface roughness, Ra. Nanoindentation

Table 1 Hole-making parameters

\begin{tabular}{lll}
\hline Parameters & Drilling & Helical milling \\
\hline Cutting speed & $66 \mathrm{~m} / \mathrm{min}$ & $66 \mathrm{~m} / \mathrm{min}$ \\
Spindle speed & $2626 \mathrm{rpm}$ & $3500 \mathrm{rpm}$ \\
Tangential feed & N/A & $0.04 \mathrm{~mm} / \mathrm{rev}$ \\
Axial feed & $0.2 \mathrm{~mm} / \mathrm{rev}$ & $0.2 \mathrm{~mm} / \mathrm{rev}$ \\
Cooling condition & Dry/lubricated & Dry $/ \mathrm{lubricated}$ \\
\hline
\end{tabular}

experiments were carried out with a nanoindenter XP from Keysight equipped with a Berkovitch diamond tip, calibrated on fused silica using the Oliver and Pharr method [18]. The coupons were allowed to thermally equilibrate with the instrument until the drift rate was measured to be below $0.1 \mathrm{~nm} / \mathrm{s}$. The indentations were carried out at a constant strain rate of $0.1 \mathrm{~s}-1$ up to $500 \mathrm{~nm}$ depth for an array of $4 \times 4$ indents, spaced $10 \mu \mathrm{m}$ in X and Y. The Young modulus (E) and hardness $(H)$ values were calculated from the stiffness on unloading at $500 \mathrm{~nm}$ depth.

\section{Results}

A comparison of the cycles to failure for different machining conditions is shown in Fig. 2. It can be seen that Al 2024-T3 alloy displays a greater ( twofold) fatigue life compared to that of the Ti-4Al-6V alloy under all machining conditions. The use of coolant lubrication generally improves the fatigue life for both alloys, except that for milled Al 2024-T3, lubricated and dry milling conditions resulted in similar fatigue life for the coupons tested. For both alloys, the helical milling significantly improved fatigue life comparing to conventional drilling process. The greatest average number of cycles to failure for both alloys is achieved with helical milling under lubrication (22,018 cycles for Al 2024-T3, and 13,039 cycles for Ti-4Al-6V). Moreover, for Al 2024-T3 alloy, the use of helical milling resulted in $63 \%$ longer fatigue life under dry condition and $18 \%$ longer fatigue life under lubricated condition comparing to conventional drilling. For Ti-4Al$6 \mathrm{~V}$, the improvement in fatigue life using helical milling is $46 \%$ and $69 \%$ for dry and lubricated conditions, respectively. 
Table 2 Fatigue test parameters

\begin{tabular}{llllllll}
\hline Material & $R$ & $F(\mathrm{~Hz})$ & $F_{\max }(\mathrm{KN})$ & $F_{\min }(\mathrm{KN})$ & $F_{\mathrm{a}}(\mathrm{KN})$ & $\sigma_{\max }(\mathrm{MPa})$ & $\sigma_{\min }(\mathrm{MPa})$ \\
\hline Al 2024-T3 & 0.1 & 5 & 10.78 & 1.08 & 4.85 & 277.5 & 27.75 \\
Ti-6Al-4V & 0.1 & 5 & 26.61 & 2.66 & 11.97 & 684.75 & 68.48 \\
\hline
\end{tabular}

Surface roughness $\left(R_{a}\right)$ values of holes produced by different machining processes are shown in Fig. 3. It can be seen that Ti-4Al-6V alloy has a rougher surface finish compared to Al 2024-T3 after machining and helical milling generally lead to lower surface roughness compared to drilled surfaces.

Optical inspection of drilled coupons (not shown here) shows that helical milling produced good quality holes in $\mathrm{Al}$ 2024-T3 with minimal roundness error and microstructural deformation. Figure 4 shows subsurface cross-sectional SEM images of Al 2024-T3 produced from different machining conditions. Plastic deformation of the grains along the machining direction is clearly evidenced in drilled coupons under both dry (Fig. 4a) and lubrication (Fig. 4b) conditions, but such layer has not been evidenced in the helical milled coupons (Fig. 4c, d). An $\sim 40 \mu \mathrm{m}$ thick recast layer or white layer has been found in certain regions of the drilled surfaces; some of which detached from the bulk and form debris (Fig. 4e).

Nanoindentation test has been carried out to characterize the mechanical properties of the recast layer formed during the dry drilling process and the hardness and Young's module results are shown in Fig. 5.

Figure 6 shows the SEM microstructural analysis for Ti6Al-4V. Drilled coupons (dry and lubricated) showed severe uniform plastic deformation region ( $\sim 15 \mu \mathrm{m}$ thick) with elongated grains. This is similar to the findings in the published literatures $[14,19,20]$. In addition, white layers with indistinguishable microstructures have been observed at the uppermost layer of drilled surfaces. In contrast, no obvious imparted subsurface deformation has been observed for milled coupons (dry and lubricated).

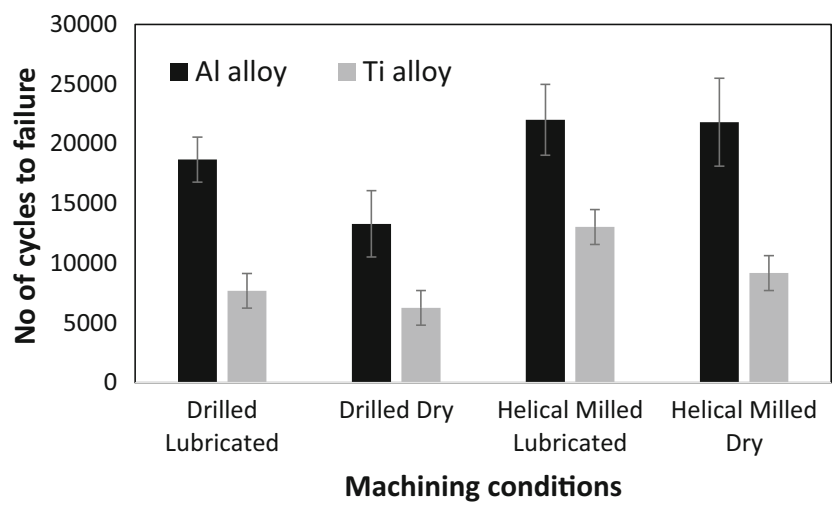

Fig. 2 A comparison of the cycles to failure for different hole-making processes. Average and standard deviation are calculated from seven tested coupons

\section{Discussions}

For both alloys, the increase of fatigue life seen for milled coupons and lubricated conditions is most likely due to the improved surface integrity of the machined parts. It can be seen that helical milling generally leads to a smoother surface compared to drilled surfaces, especially under the dry condition. The presence of lubrication further reduces the surface roughness for both machining processes. The surface roughness produced by drilling (dry) is the highest ( $\mathrm{Ra} \sim 0.875 \mu \mathrm{m}$ ) amongst all measurements. It is known that the fatigue test can serve as a first-order approximation for fatigue crack initiation [21] and the greater surface roughness of coupons machined by drilling without cutting fluid was most likely the greatest contributor to the reduction in fatigue life. The rougher surfaces and presence of notches, particularly in drilled specimens, meant greater stress concentrations which provide fatigue crack initiation sites, and a subsequent reduction in fatigue life [22]. Recently, several researchers deployed the 3D finite element method (FEM) to model the helical milling process of Ti-6Al-4V, and different tool geometries have been considered [17, 23]. Our FEM model on flat helical milling tool and its associated experimental validation suggested that for helical milling of Ti-6Al-4V, the cutting force required was smaller than that of other traditional drilling processes. This infers a lower stress experienced by the machined surface, less severe tool wear and hence a better surface quality of the borehole and smaller deformation around the borehole [17].

Conventional drilling induces greater surface damage and more significant microstructural changes compared with milled surfaces; this could also be attributed to the greater heat generated. For Al 2024-T3, the formation of

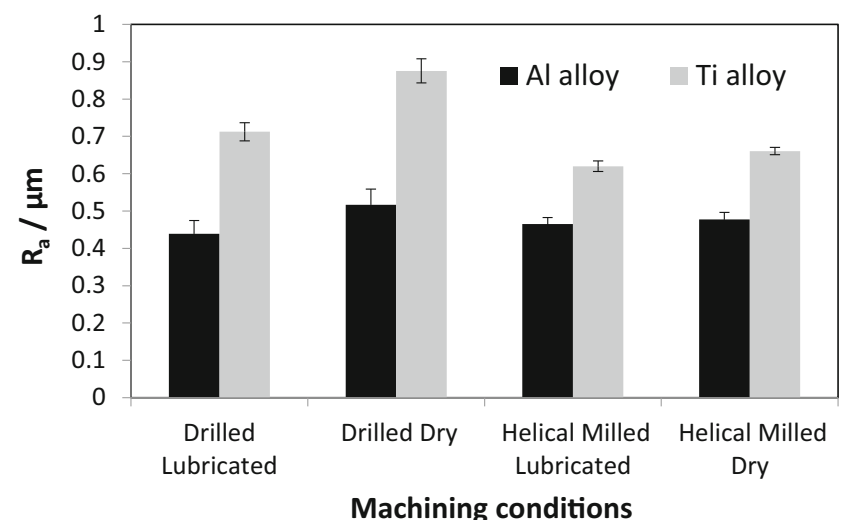

Fig. 3 Average surface roughness measurements of hole surfaces of $\mathrm{Al}$ 2024-T3 and Ti-4Al-6V 
Fig. 4 SEM images of holes made on Al 2024-T3 alloy by a dry drilling, b lubricated drilling, c dry helical milling, $\mathbf{d}$ lubricated helical milling and $\mathbf{e}$ a recast layer or white layer on dry-drilled $\mathrm{Al}$ 2024-T3 hole surface
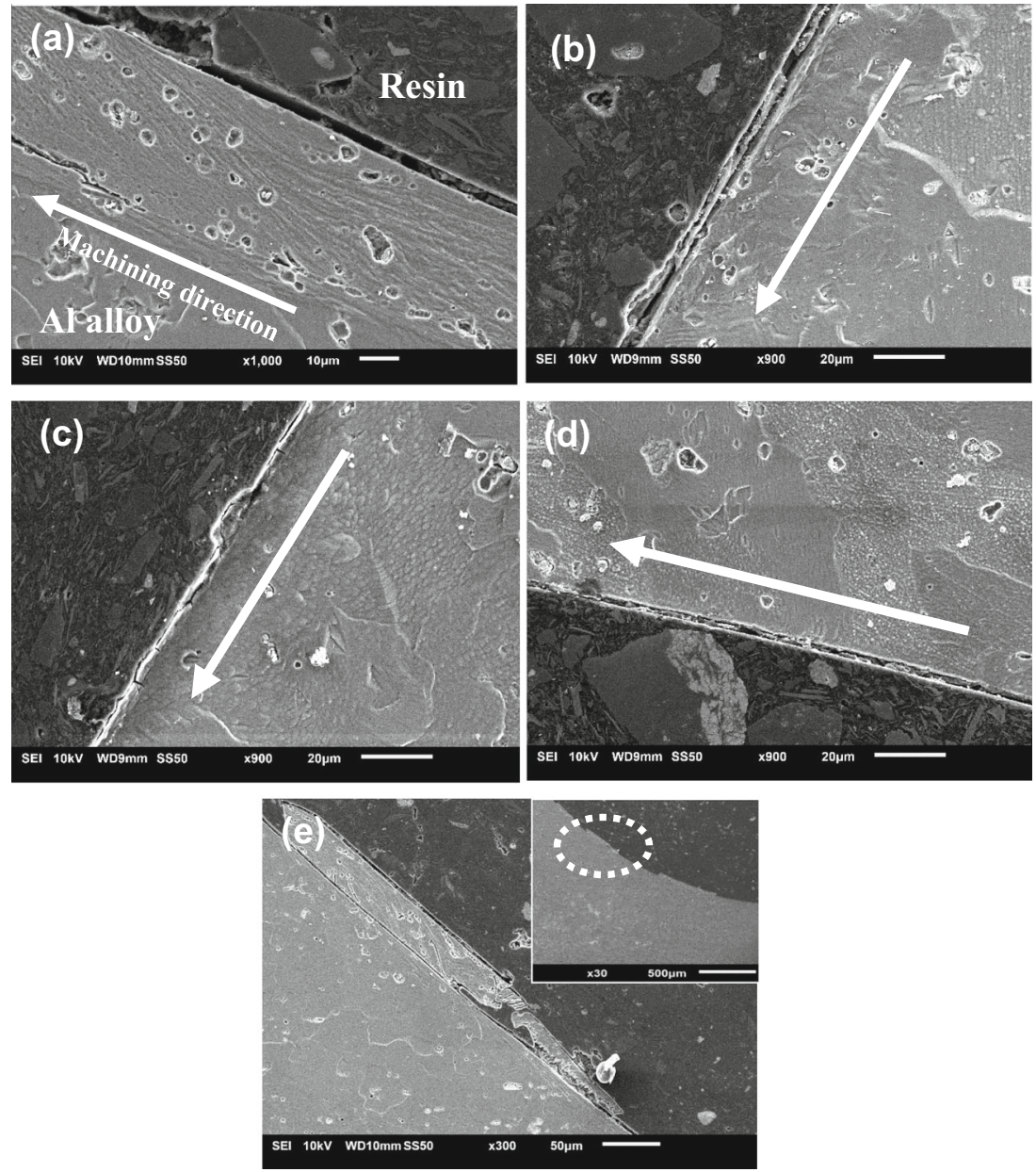

the plastically deformed region found in the drilled coupon subsurface can be a combined result of elevated temperature and the mechanical stresses resulting from the continuous drilling operation [24]. The $\sim 40-\mu \mathrm{m}$ thick recast layer that presents in some regions of the dry-drilled hole surface could be due to the melting induced by the high temperature of the dry drilling process. This left over molten material re-solidifies on the surface of workpiece during cooling and is considered to have negative effects on the life of the components machined [25, 26]. Nanoindentation results show that both hardness and Young's modulus of such layer is lower than that of the bulk, and the weakened mechanical properties may be attributed to the thermal softening effect. The fracturelike surface morphology observed in the milled coupons (Figs. 4c) could be due to microsegments of alloy has undergone local work hardening and subsequently separated by a local brittle fracture [27].

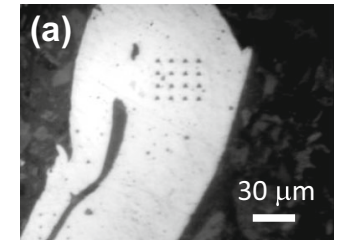

(b)

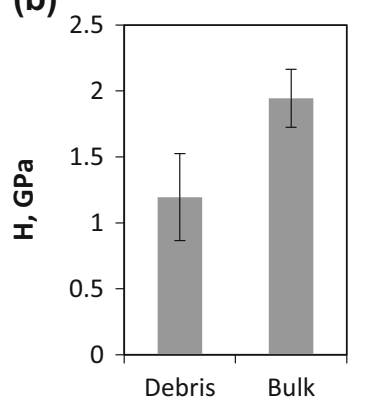

(c)

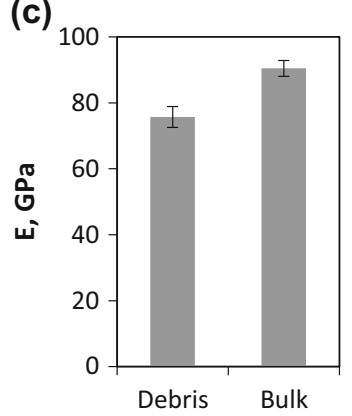

Fig. 5 Nanoindentation measurements on a dry-drilled Al alloy recast layer. a An optical micrograph of the array of indents performed on a delaminated flake, near the edge of the drilled hole, as seen in Fig. 4e. b
Hardness data. c Young modulus data. The bulk values are measured within the coupon piece, away from the flake, and are statistically larger than the flake ( $p$ values $<0.05$ ) 
Fig. 6 SEM images of holes made on Ti-4Al-6V alloy by a dry drilling, b lubricated drilling, c dry helical milling and $\mathbf{d}$ lubricated helical milling
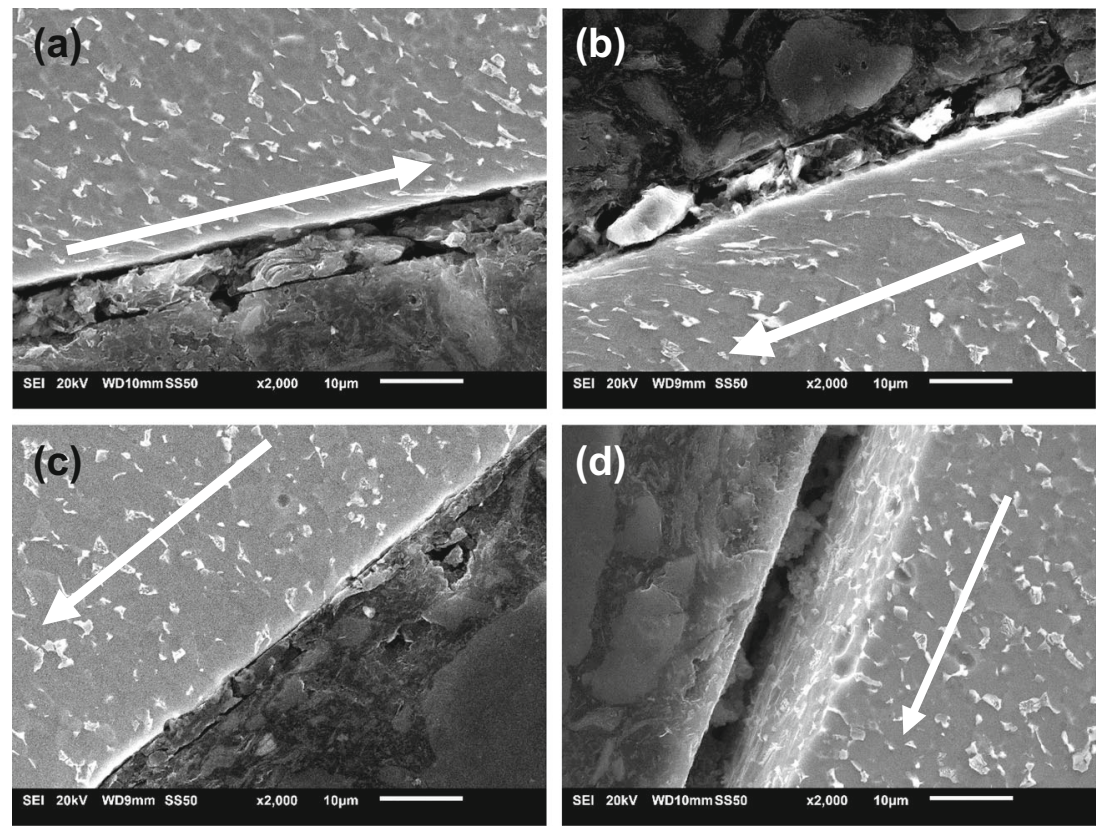

In machining of Ti-6Al-4V, white layer appeared intermittently on drilled surfaces. The absence of severe subsurface plastic deformation and white layer in milled coupons could be again associated to the decreased thrust and cutting forces (therefore reduced strain rate on material) of the helical milling process and the lower processing temperature. A detailed investigation on the subsurface microhardness of Ti-6Al-4V alloy subjected to drilling and helical milling processes has been previously carried out by the present authors [28]. During the drilling process, the higher temperatures generated combined with the low thermal conductivity of Ti-6Al-4V could lead to thermal softening, which in turn increased the contact area between the tool and workpiece causing a significantly deformed layer [29]. For helical milling, the strain hardening effect plays a more dominant role due to the greater mechanical energy input, lower cutting temperature and better heat dissipation. The maximum subsurface microhardness value in helical milling has been reported to be $18 \%$ higher than that of the bulk material in our previous report [28]. One of the recent studies deployed a physics-based FEM to predict the effect of machining (2D orthogonal cutting) on the phase transformation and grain size growth of Ti-6Al-4V [30]. Greater volume fraction of $\beta$ phase and decreased grain size have been predicted when cutting speed is increased from $21.8,43.6$, to $65.4 \mathrm{~m} / \mathrm{s}$. Despite the different modes of machining, it is likely that our materials at the tool/metal interface have undergone similar grain size variation and phase transformation. However, this is not the main focus of the present research, and future work will be planned in this direction.

Overall speaking, the fatigue results obtained for both alloys are consistent with the roughness measurement data and the microstructural observation. In particular, machining conditions involving drilling without lubrication led to the greatest surface damage/plastic deformation. This means there are greater stress concentrations present on the machined surface which provide fatigue crack initiation sites, and a subsequent reduction in fatigue life of the coupons. In contrast, helical milling with lubrication condition gives rise to longer fatigue life of the alloys. Such condition resulted in the best hole quality (least roughness) and the material microstructure is least affected. In addition, the residual stress present in the hole surface can be another factor contributing to the fatigue behavior of the alloys [28]. The tensile residual stress measured for drilled surface is expected to reduce the fatigue life of the workpiece, while the compressive residual stress measured for the milled coupon can effectively extend its fatigue life [31].

\section{Conclusions}

In this study we investigated the impacts of two hole-making processes, namely conventional drilling and helical milling, on the machined hole microstructures and fatigue behavior of two aircraft alloys, Ti-6Al-4V and Al 2024-T3. Results show that the helical milling results in less severe material plastic deformation which in turn leads to a longer fatigue life as compared to conventional drilling. This can be attributed to the intermittent cutting behavior, good heat dissipation and lower cutting force of the helical milling process. The use of lubricant helps to reduce the surface roughness and improve the fatigue life. In addition, the residual stress in the hole surface can be another contributing factor to the different fatigue behavior of the alloys. The presented work shows that helical milling process can be considered as a promising manufacturing technology for aircraft alloy machining. In 
order to further validate the efficiency of helical milling process in the aircraft assembly industry, further research is still required, especially on the helical milling of stacked carbon reinforced plastics (CFRP)/alloy structures. CFRP and aircraft alloys are distinctly different materials hence may require different machining parameters to achieve the ideal hole quality. This makes the hole-making process on stacked structures remain a significant challenge. The emerging helical milling could be coupled with advanced automation/intelligent manufacturing technology [32-34] to minimize/eliminate the labor intensive and error-prone human operation. In addition, feature-based manufacturing parameter planning and optimization [35-37] could be considered in future aircraft holemaking processes to enhance accuracy, traceability and process control.

Acknowledgements Funding support from Engineering and Physical Science Research Council in the UK under Project No. EP/K004964/1 is acknowledged. Funding support from NSF China (No. 51420105007) is acknowledged. The authors would also like to thank Mr. Michael Oprey from Vulcanium Metals International for supplying the Ti-6Al-4V alloy.

\section{Compliance with ethical standards}

Conflict of interest The authors declare that they have no conflict of interest.

Open Access This article is distributed under the terms of the Creative Commons Attribution 4.0 International License (http:// creativecommons.org/licenses/by/4.0/), which permits unrestricted use, distribution, and reproduction in any medium, provided you give appropriate credit to the original author(s) and the source, provide a link to the Creative Commons license, and indicate if changes were made.

\section{References}

1. Riley A, Aardema, B, Vosbury P, Eiff MA, Frautschy HG, Serkenburg R, Shaffer D, Wild T, Michmerhuizen T (2008) Aviation maintenance technician handbook. Department of Transportation: Federal Aviation Administration. Newcastle, Wash

2. Zhang S, Zhao D (2012) Aerospace materials handbook. CRC Press

3. Iyer R, Koshy P, Ng E (2007) Helical milling: an enabling technology for hard machining precision holes in AISI D2 tool steel. Int J Mach Tools Manuf 47(2):205-210

4. Gu W, Xu H, Liu J, Yue Z (2009) Effect of drilling process on fatigue life of open holes. Tsinghua Sci \& Tech 14(S2):54-57

5. Liu J, Xu HL, Zhai HB, Yue ZF (2010) Effect of detail design on fatigue performance of fastener hole. Mater Des 31(2):976-980

6. Zhang PF, Churi NJ, Pei ZJ, Treadwell C (2008) Mechanical drilling processes for titanium alloys: a literature review. Mach Sci Technol 12(4):417-444

7. Latger F, Harris T, Björklund S (2002) Drilling cost model. SAE Technical Paper 2002-01-632

8. Qin XD, Sun XT, Wang Q, Chen SM, Li H (2012) Comparative study on helical milling and drilling of Ti-6Al-4 V. Key Eng Mat 499:200-204
9. Sasahara H, Kawasaki M, Tsutsumi M (2008) Helical feed milling with MQL for boring of aluminum alloy. J Adv Mech Des Syst \& Manuf 2(6): 1030-1040

10. ISO 286-2:2010. Geometrical product specifications (GPS) - ISO code system for tolerances on linear sizes - part 2: tables of standard tolerance classes and limit deviations for holes and shafts

11. Li H, He G, Qin X, Wang G, Lu C, Gui L (2014) Tool wear and hole quality investigation in dry helical milling of Ti-6Al-4V alloy. Int J Adv Manuf Technol 71(5):1511-1523

12. Olvera D, De Lacalle LNL, Urbikain G, Lamikiz A, Rodal P, Zamakona IH (2012) Hole making using ball helical milling on titanium alloys. Mach Sci Technol 16(2):173-188

13. Sun J, Guo YB (2009) A comprehensive experimental study on surface integrity by end milling Ti-6Al-4V. J Mater Process Technol 209(8):4036-4042

14. Che-Haron $\mathrm{CH}$, Jawaid A (2005) The effect of machining on surface integrity of titanium alloy Ti-6\% Al-4\% V. J Mater Process Technol 166(2):188-192

15. Che-Haron CH (2001) Tool life and surface integrity in turning titanium alloy. J Mater Process Technol 118(1-3):231-237

16. Dornfeld DA, Kim JS, Dechow H, Hewson J, Chen LJ (1999) Drilling burr formation in titanium alloy, Ti-6Al-4V. CIRP Annals - Manuf Tech 48(1):73-76

17. Ji CH, Li YH, Qin XD, Zhao Q, Sun D, Jin Y (2015) 3D FEM simulation of helical milling hole process for titanium alloy Ti-6Al4V. Int J Adv Manuf Technol 81(9):1733-1742

18. Oliver WC, Pharr GM (1992) An improved technique for determining hardness and elastic modulus using load and displacement sensing indentation experiments. J Mat Res 7(6):1564-1583

19. Leyens C, Peters M (2003) Titanium and titanium alloys: fundamentals and applications. Wiley-VCH, Weinheim

20. Hughes JI, Sharman ARC, Ridgway K (2004) The effect of tool edge preparation on tool life and workpiece surface integrity. Proc Inst Mech Eng Pt B: J Eng Manuf 218(9):1113-1123

21. Reissig L, Völkl R, Mills MJ, Glatzel U (2004) Investigation of near surface structure in order to determine process-temperatures during different machining processes of Ti6Al4V. Scr Mater 50(1): 121-126

22. Pei X, Chen W, Ren B, Han Y (2002) Effect of drilling processes on surface integrity of 7075-aluminum alloy holes. J Beijing University of Aeronautics and Astronautics 28(3):319-322

23. Rey PA, LeDref J, Senatore J, Landon Y (2016) Modelling of cutting forces in orbital drilling of titanium alloy Ti-6Al-4V. Int J Machine Tools \& Manufacture 106:75-88

24. M'Saoubi R, Axinte D, Soo SL, Nobel C, Attia H, Kappmeyer G, Engin S, Sim WM (2015) High performance cutting of advanced aerospace alloys and composite materials. CIRP Annals-Manuf Tech 64(2):557-580

25. Xu JK, Xia K, Xu Z, Zhang LS, Yu ZJ, Yu HD (2015) Study on hardness and tribological properties of highspeed wire electrical discharge machining surface. International Conference on Mechatronics and Automation, Beijing

26. Arooj S, Shah M, Sadiq S, Jaffery SHI, Khushnood S (2014) Effect of current in the EDM machining of aluminum 6061 T6 and its effect on the surface morphology. Arab J Sci \& Eng 39(5):41874199

27. Songmene V, Khettabi R, Zaghbani I, Kouam J, Djebara A (2011) Machining and machinability of aluminum alloys. In: Kvackaj T (ed) aluminium alloys, theory and applications. InTech. DOI: $10.5772 / 14888$

28. Zhao Q, Qin X, Ji C, Li Y, Sun D, Jin Y (2015) Tool life and hole surface integrity studies for hole-making of Ti6Al4V alloy. Intl J Adv Manuf Tech 79(5):1017-1026

29. Nouari M, Makich H (2014) On the physics of machining titanium alloys: interactions between cutting parameters, microstructure and tool wear. Metals 4(3):335-358 
30. Pan Z, Liang SY, Garmestani H, Shih DS (2016) Prediction of machining-induced phase transformation and grain growth of Ti6Al-4 V alloy. Int J Adv Manuf Technol 87(1):859-866

31. Yao CF, Tan L, Ren JX, Lin Q, Liang YS (2014) Surface integrity and fatigue behaviour for high-speed milling Ti-10V-2Fe-3Al titanium alloy. J Fail Anal Prev 14(1):102-112

32. Li Y, Lee CH, Gao J (2015) From computer-aided to intelligent machining: recent advances in computer numerical control machining research. Proc IMechE Part B: J Engineering Manufacture 229(7):1087-1103

33. Liu C, Li Y, Hao X (2016) An adaptive machining approach based on in-process inspection of interim machining states for largescaled and thin-walled complex parts. Int J Adv Manuf Technol DOI. doi:10.1007/s00170-016-9647-4
34. Liu C, Li Y, Shen W (2014) Integrated manufacturing process planning and control based on intelligent agents and multi-dimension features. Int J Adv Manuf Technol 75(9): $1457-1471$

35. Liu LY, Zhou X, Shen W (2015) Interim feature-based cutting parameter optimization for aircraft structural parts. Int J Adv Manuf Technol 77(1):663-676

36. Li Y, Liu X, Gao J, Maropoulos P (2012) A dynamic feature information model for integrated manufacturing planning and optimization. CIRP Annals - Manuf Tech 61(1):167-170

37. Liu X, Li Y, Gao J (2016) A multi-perspective dynamic feature concept in adaptive NC machining of complex freeform surfaces. Int J Adv Manuf Technol 82(5):1259-1268 